\title{
Allocation of Emission Allowances within the European Union Emissions Trading Scheme to the Waste Sector
}

\author{
Nina Braschel, Alfred Posch, Vera Pusterhofer \\ Institute of Systems Sciences, Innovation and Sustainability Research, University of Graz, Graz, Austria. \\ Email: nina.braschel@uni-graz.at
}

Received July $12^{\text {th }}, 2013$; revised August $10^{\text {th }}, 2013$; accepted August $18^{\text {th }}, 2013$

Copyright (c) 2013 Nina Braschel et al. This is an open access article distributed under the Creative Commons Attribution License, which permits unrestricted use, distribution, and reproduction in any medium, provided the original work is properly cited.

\begin{abstract}
The present study develops an approach explicitly to cover the waste sector under the Emissions Trading Scheme of the European Union (EU ETS). The objective is to analyze various allocation possibilities and the resulting monetary burdens for the waste sector. Three different allocation variants for allocating emission allowances and their financial burden to the waste sector are developed. These variants support implementation within the EU ETS in the third trading period from 2013 to 2020. The respective distributions of emission allowances to the Austrian waste sector are estimated for each variant calculated. Allowances vary depending on specific industry, the relative share of free and purchased allowances, and the relative costs entailed in additional purchase. Although the present paper focuses explicitly on the Austrian waste sector, in principle, the calculation procedure is applicable to waste sectors in other developed countries as well.
\end{abstract}

Keywords: Allocation of Emission Allowances; Distribution of Free/Purchased Allowances; European Union Emissions Trading Scheme; Financial Burden; Waste Sector

\section{Introduction}

As part of the Kyoto agreement in 1997, the European Union (EU) committed itself to reducing by 2012 climate effective emissions by 8 percent below the 1990 emissions level. The Kyoto protocol defined three flexible mechanisms for reaching the reduction targets: Joint Implementation (JI), the Clean Development Mechanism (CDM) and Emission Trading (ET) [1-5].

When using the trading of emission allowances as a climate-policy instrument, a limit or cap is set for the total amount of emissions allowed. This emissions limit can then be reached by countries trading emission allowances in a cost-effective and economically efficient manner [1-7]. The basic idea is that one emission allowance is needed for every ton of GHG emissions produced.

The Emissions Trading Scheme of the EU (hereafter EU ETS) covered the sectors energy and industry in its first (2005-2007) and second (2008-2012) trading period, but not the waste sector. While a few studies show how the waste sector can contribute to climate protection, and how the actors of the waste sector can generate economic profits, mainly by participating in one of the two project- based flexible mechanisms JI and CDM (see, e.g., [8]), no existing study has yet described precisely how, and under which circumstances, inclusion of the waste sector in the EU ETS might be possible and what the consequences might be. The present study takes the economic model lying behind the emission allowance allocation and develops three allocation variants in order to reflect the different allocation possibilities available for the waste sector (it is assumed here that the waste sector will actually be included in the third EU ETS trading period (2013-2020)).

The objective is to analyze different allocation possibilities and their respective monetary burdens so as to assess the potential financial impact of an inclusion of the Austrian waste sector.

While the data used and outcomes calculated are based specifically on the Austrian waste sector, the concept can be applied generally to assess the impact of waste sector inclusion in other similar countries.

The paper is divided into four further sections. Section 2, provides basic information on the EU ETS. Section 3, offers a suitable definition for the term "waste sector". In Section 4, the basic economic model is described. This 
section also contains explanations of related allocation rules and variables, of parameters and assumptions, and of the three allocation variants calculated. In addition, data from the Austrian waste sector are applied to the model in order to calculate different allocation possibilities. The potential impact of waste sector inclusion on emission allowance quantities and related funding is thus made visible. The results for the different allocation possibilities and their respective financial burdens are revealed in Section 5. The last section, Section 6, discusses the limitations of the approach and some conclusions are drawn for future research.

\section{The European Union Emissions Trading Scheme}

The EU ETS is the world's biggest cap-and-trade system. By enabling emission allowance trading among the 27 EU member states, plus Iceland, Liechtenstein and Norway, it has created an economically cost-efficient means for reaching Kyoto emission targets. To date, at the end of the second trading period, the regulation system covers industrial sectors of energy conversion and energy transformation, iron and steel production and processing, the mineral industry (cement, lime, glass, ceramics, brick) and other industrial branches (pulp, paper, board), the sectors nitric acid, petrochemicals, ammonia and aluminium, as well as the aviation sector., The emissions regulated by the EU ETS include $\mathrm{CO}_{2}$ and $\mathrm{N}_{2} \mathrm{O}$ from the production of nitric, adipic and glyoxylic acids, as well as PFCs from the aluminium sector [2,9-11].

The EU ETS was first launched in 2005 and has since been divided into three trading periods. The first pilot phase was from 2005 to 2007. The data gained during this testing period was used as a basis for the second, trading phase, which began in 2008, and which is due to end in 2012. The third implementation phase will span the years 2013 to 2020 .

The basic principle of the EU ETS is that every operator of an industrial installation subject to EU ETS regulation is required to have a permit for every ton of $\mathrm{CO}_{2}$ emissions emitted. Some energy-intensive industries whose competitiveness was judged to be at risk and who are therefore potentially prone to carbon leakage may be exempted [7,12-15].

The initial allocation of the emission allowances in the first two phases is covered in national allocation plans (hereafter NAPs). For these two periods the EU member states set their own individual caps on emissions allowances. In addition to sectoral and branch allocations the respective NAPs also determine allocations at the plant level. Every member state NAP has to be confirmed by the European Commission [2,10,11,16].

The vast majority of all allowances distributed during the first and second trading periods were given out free of charge. As various problems arose with this approach, it was decided that from 2013 onwards auctioning would form the basis for allocating allowances. A progressive transition to auctioning is planned, starting with a 20 percent share of allowances distributed in 2013, and reaching full auctioning in 2027 [4,5,13-15,17].

\section{Definition of the Term "Austrian Waste Sector"}

No matter how often the topic "waste" is studied, defining the term "waste management", "waste sector" or "waste industry" seems to become more, rather than less, problematic.

Obviously, before any meaningful discussion concerning an incorporation of the waste sector into the EU ETS can take place at all, a clear definition of what is meant by the term is needed, e.g. which areas are to be included and which excluded [18].

The objective in the present paper is to calculate the different possibilities concerning inclusion of the Austrian waste sector in the EU ETS. For this purpose, the standard definition was considered adequate and was adopted here. This definition covers four basic divisions [1,19-22]:

1) Solid waste disposal on land/landfills;

2) Wastewater treatment;

3) Waste incineration;

4) Other waste treatment (composting, mechanicalbiological treatment).

The decision to adopt the standard definition was based on the following:

1) To date, the EU ETS only includes carbon dioxide emissions $\left(\mathrm{CO}_{2}\right)$. Two exceptions are Austria and the Netherlands where nitrous oxide emissions $\left(\mathrm{N}_{2} \mathrm{O}\right)$, caused by the production of nitric acid $\left(\mathrm{HNO}_{3}\right)$, are now considered in the second trading period (2008-2012). Within the above four divisions only waste incineration facilities cause $\mathrm{CO}_{2}$ emissions. However, for the present study methane $\left(\mathrm{CH}_{4}\right)$ and $\mathrm{N}_{2} \mathrm{O}$ also need to be considered.

2) The position of the European Parliament (EP) on the improvement and extension of the trading scheme says that "...the Community scheme should be extended to other installations [...] which are capable of being monitored, reported and verified with the same level of accuracy as that which applies under the monitoring, reporting and verification requirements currently applicable.” [23] Although the EP is pushing to extend the scheme to other installations, it is debatable whether installations of the waste sector can fulfil the necessary requirements [24].

3) The term "waste incineration facilities" covers in- 
cineration plants for municipal waste and other thermal waste treatment facilities. These facilities lead to $\mathrm{CO}_{2}$, but are only responsible for a small part of all greenhouse gas (hereafter GHG) emissions in the waste sector [21, $22,25]$. Moreover, incineration plants with energy recovery and co-combustion plants are classed as belonging to the sectors energy and industry and are therefore already included in the EU ETS. This results in a (seemingly) relatively low level of emitted carbon within the waste sector. For purposes of the present study, the fact that the European Union Emissions Trading Scheme mainly addresses carbon dioxide emissions is reason enough to include this subsector in the definition of the Austrian waste industry.

4) With regard to climate effective gases, $\mathrm{CH}_{4}$ comprises the majority of all GHG emissions in the waste sector (80\% in Austria in 2010). The main driver of $\mathrm{CH}_{4}$ emissions is solid waste disposal on land (with a share of 75\% in Austria in 2010) [21]. Various council directives and amendments governing landfill, e.g. 1999/31/EC, regulation No. 1882/2003 and No. 1137/2008, and the EU Waste Framework Directive 2006/12/EC. The disposal restriction of waste containing more than five percent organic carbon (in terms of mass) was the most important measurement to reduce $\mathrm{CH}_{4}$ from landfills [26, 27].

5) Although recent restrictions on waste disposal are rigorous, the waste deposited in earlier periods is still there and still causing GHG emissions. However, so far, $\mathrm{CH}_{4}$ emissions are still not considered in the EU ETS, nor is there any direct evidence that they might be included in the near future $[12,23]$. Nevertheless, this subsector could not be taken out of account at all and has therefore be considered in the present calculation.

6) While $\mathrm{N}_{2} \mathrm{O}$ emissions mainly arise from wastewater treatment, they also occur in waste treatment facilities such as composting plants. Hence, the present definition includes both wastewater treatment and composting facilities.

The allocation variants calculated here are based on theoretical assumptions. The intention is simply to gain a better understanding of the future possibilities with respect to the interface between the EU ETS and the waste sector. Nonetheless, inclusion of the waste sector in the EU ETS is a clear legal option. This is stated in the original directive 2003/87/EC and also in revised form in 2009/29/EC. Article 24 points out that subject to commission agreement, and assuming specific criteria are met, various activities and installations can be incorporated into the regulatory system at the national level. The alternative would be a reconfiguration of the whole

\section{European ETS.}

\section{Method}

This section provides a basic description of the economic model employed and includes explanations of the respective allocation rules, parameters and assumptions used in calculating the three cases. The relationship between allocation type (i.e. Variant 1, 2 or 3) and expected financial burden upon inclusion of the waste sector, is also given.

\subsection{Economic Model for Allocating Emission Allowances}

Different kinds of allocation mechanisms are described in the literature. The three most common are:

1) Grandfathering: this uses historical data on emissions as a basis for the future allocation of emission allowances [13,16,28].

2) Benchmarking: here, the best available technique is used as the basis for emission allowance allocation $[13,14,28]$.

3) Auctioning: under this procedure, instead of direct allocation, emission permits are auctioned according to demand $[13,14]$.

In the first and second trading period of the EU, ETS emission allowances were distributed based on the grandfathering mechanism and subsequently on country-specific, independently determined NAPs [2,4,16,29]. In drawing up the initial NAP each country used the historical $\mathrm{CO}_{2}$ emission data for the installations covered by the EU ETS as a basis for calculation. Directive 2003/ 87/EC defines the relevant criteria for establishing NAPs. These are valid for all member states and are listed in Annex III of the directive. Unfortunately, allocation methods across countries still vary considerably, making uniform emission comparison difficult [29].

To aid understanding, the distribution methods used in Austria are now stated below. The type of distribution is first stated in terms of a standard equation, and is then followed by a textual description (see [30,31]). Since most of the parameters are used in more than one equation, a more detailed description of all individual parameters is also presented in a more comprehensible form subsequent to the economic model in the next section, Section 4.2.

When beginning a new trading period within the EU ETS, an overall greenhouse gas emissions level, i.e. a cap for the allowances to be distributed, first needs to be defined.

Equation (1): Defining the total quantity (emissions cap)

$$
\text { Total Quantity }=\text { Emission Forecast }_{t 0-t n}-\left(1-\sum \text { Climate Protection Contribution }_{t 0-t n ~ s e c t o r}\right)
$$


The total quantity of emission allowances allocated to a country is obtained by taking the total from the emission forecast for the period (in the present study the period 2013-2020), and then subtracting the sum of all mandatory climate protection contribution factors for the period for all sectors included.

Equation (2): Defining sectoral emission allowances (see Equation (2)).

The quantity of emission allowances allocated to one sector is given by finding the total of business-as-usual forecasts for all industries (sub-sectors) in the sector, in the present case all four industries of the waste sector, and then subtracting the product of the climate protection contribution for the respective sector, multiplied by the relevant reserve factor (this was taken to be 1 percent in the present study).

Equation (3): Defining amount of free allocation for the sector

$$
\begin{aligned}
\text { Free Allocation }_{\text {sector }}= & \text { Allocation }_{\text {sector }} \\
& -\left(1-\text { Auctioning Share }_{\text {sector }}\right)
\end{aligned}
$$

To define the amount of emission allowances distributed free of charge to a specific sector, the auctioning share per sector, in the present case a constant share of 20 percent, has to be deducted from the total quantity of emission allowances allocated to the respective sector.

Equation (4): Defining amount of free allocation for a specific industry (see Equation (4))

The quantity of emission allowances allocated free of charge at the industry level is obtained by multiplying the allocation base of the respective industry by the growth factor of the industry's emissions, by the potential factor of the industry, and by the respective compliance factor (this is the same for all industries within a single sector).

Equation (5): Defining growth factors for industry emissions

$$
\text { Growth Factor }_{\text {industry }}=\frac{\text { Business As Usual }_{\text {industry }}}{\text { Allocation Base }_{\text {industry }}}
$$

The growth factor for an industry captures the expected development in the industry's greenhouse gas emissions. The business-as-usual forecasts are used as a basis for determining the expected future growth rate of the industry's emissions.

\subsection{Parameters and Assumptions}

As far as the present analysis is concerned, the model focus is placed on the sectoral and industry level. Each allocation variant determines the number of emission allowances distributed to the respective sector and its industries. In the following calculations, apart from the level of the climate protection contribution, all variables are kept constant. The crucial difference in the three allocation variants is therefore the assumption about the level of the climate protection contribution factor.

Based on data from the Environment Agency Austria the average expected GHG emissions up to 2020, as well as an emission projection for the third trading period, are calculated and presented in Table 1. This is the basis for all three allocation variants calculated. The allocation base and the growth factor for each industry are also given in this table. The parameters and assumptions used are now described below.

1) Allocation base: The allocation base, in the present case of an industry, reflects an industry's average emissions level within the previous trading period or within that of another stated period. In the present study the emission levels of 2008 and 2009 were extrapolated to obtain values for the period 2008 till 2012, which was then used as the allocation base (see Table 1).

2) Auctioning share: Within the EU ETS 20 percent of allowances are to be made available via auctioning in 2013, so this share was also adopted for the present study [12]. An auctioning share of 20 percent means that 80 percent of the potential allocation of emission allowances in the Austrian waste sector are handed out for free and 20 percent have to be purchased via auctioning at the beginning of the trading period.

3) Business-as-usual forecast: Business-as-usual forecasts calculate an industry's future GHG emissions level, assuming that certain factors remain constant. Historical trends for production volumes or energy intensities are extrapolated into the future in order to establish an industry's potential demand for emission allowances. The sum of business-as-usual forecasts for those industries belonging to the respective sector leads to the expected amount of GHG emissions at the sectoral level (see Table 2).

4) Climate protection contribution factor: The climate protection contribution is the amount by which GHG emissions need to be reduced within a respective trading period. This factor has a huge influence on the distribution of emission allowances and reflects the difference between the amount of GHG emissions in a business-asusual scenario and the set target-value for a certain year.

$$
\text { Allocation }_{\text {sector }}=\left(\sum \text { Business As Usual }_{\text {industry }}-\left(1-\text { Climate Protection Contribution }_{\text {sector }}\right)\right) \cdot\left(1-\text { Reserve Factor }_{\text {sector }}\right)
$$

Free Allocation $_{\text {industry }}=$ AllocationBase $_{\text {industry }} \cdot$ Growth Factor $_{\text {industry }} \cdot$ Potential Factor $_{\text {industry }} \cdot$ Compliance Factor $_{\text {sector }}$ 
Table 1. Allocation base (2008-2012), emission projection and growth factor (2013-2020).

\begin{tabular}{cccc}
\hline Industry & $\begin{array}{c}\text { Annual Emissions in base period 2008-2012 } \\
\text { (derived as average of the past emissions of } \\
\text { 2008, 2009) }\left(\mathrm{Gg} \mathrm{CO}_{2} \text {-eq. per year) }\right.\end{array}$ & $\begin{array}{c}\text { Emission projection average annual emission } \\
\text { 2013-2020 (derived as average of projected years } \\
\text { 2010, 2015, 2020) (Gg CO } \text {-eq. per year) }\end{array}$ & Growth factor \\
\hline Landfills & 1517.1 & 995.4 & 0.656 \\
Composting facilities & 165.1 & 162.4 & 0.984 \\
Incineration facilities & 12.3 & 12.0 & 0.976 \\
Wastewater handling & 287.8 & 290.0 & 1.008 \\
Total (waste sector) & 1982.3 & 1459.8 & \\
\hline
\end{tabular}

Source: Own composition, partly based on [21,22].

Table 2. Business-as-usual projection for GHG emissions in 2010, 2015 and 2020.

\begin{tabular}{cccc}
\hline Industry & $\mathrm{Gg} \mathrm{CO}_{2}$ equivalent 2010 & $\mathrm{Gg} \mathrm{CO}_{2}$ equivalent 2015 & $\mathrm{Gg} \mathrm{CO}_{2}$ equivalent 2020 \\
\hline Landfills & 1348.2 & 951.3 & 686.7 \\
Composting facilities & 166.2 & 171.4 & 149.6 \\
Incineration facilities & 12.0 & 12.0 & 12.0 \\
Wastewater treatment & 286.6 & 289.7 & 294.8 \\
Total (Gg) & 1812.0 & 1424.4 & 1143.1 \\
\hline
\end{tabular}

Source: Own composition, partly based on [22].

While the climate protection contribution factor has a direct impact on allowance distribution, it also has a marked influence on costs. To be more precise, the lower the factor, the higher the amount of distributed emission allowances in the initial phase of the allocation process, and therefore the higher the costs for such allowances at the beginning of the trading period. However, such cost calculations do not take into account the additional costs which may arise when more emission allowances are needed than those distributed in the initial phase. In the present study three climate protection contribution factor levels were used: i.e. $0 \%, 5 \%$ and $10 \%$. A climate protection contribution level of 5 percent means that the business-as-usual emissions value in 2020 needs to be reduced by 5 percent within the trading period 20132020. In practice, the factor is set by the government of each EU member state. For purposes of the present study, this was the only factor which was allowed to vary. All other model factors were held constant. The variant with a $0 \%$ climate protection contribution factor was calculated to show that even without such a reduction target the actors of the waste sector would still have to face and cope with additional costs should the waste sector be incorporated into the EU ETS.

5) Compliance factor: This factor is intended to ensure that the free allocation of emission allowances to an industry is proportionate to the free allowances available at the sectoral level. It is the same for all industries within one sector. A compliance factor of e.g. 0.8 means that an industry is called upon to reduce GHG emissions by 20 percent, e.g. by the introduction of cleaner technology, within the trading period 2013-2020. [30,31,32]

6) Emission forecast: The emission forecast is the expected amount of GHG emissions of a certain period in the absence of additional measures for GHG emission mitigation. This then enables business-as-usual scenarios to be estimated. These are then calculated for each industry and summed in order to produce the overall emission projection for the industry (Table 1).

7) Growth factor: The growth factor of an industry shows how an industry's emission level has grown across trading periods. In the present case, the factor shows the growth rate of the emission forecast for the 2013 to 2020 period compared to the emission level in the 2008 to 2012 period (see Table 1).

8) Potential factor for emission reduction: This factor describes the technical GHG reduction potential of the sector. A factor of 1 means no emission reduction potential is available, 0 indicates that technical possibilities exist for reducing all GHG emissions to zero [30,31]. Obviously, this factor is largely determined by the potential for technical progress. Since specific information concerning the reduction potential of individual installations or industries of the waste sector is not available, and since the potential factor is the same for all four industries within the waste sector and has no impact on the results calculated, in the present study the value for the reduction potential factor is kept constant $(=1)$ over all 
three allocation variants calculated.

9) Reserve factor: Such a factor is assigned to every sector participating in the EU ETS. In the present case, the factor was set at $1 \%$, i.e. $99 \%$ of a sector's allowances are distributed either free of charge or by auctioning. The residual 1 percent is reserved to express the potential impact of new market entries. [32,33]

10) Cost calculation: The average price for the six month period March to August 2011 was used here. This was $€ 14.68$ per ton of $\mathrm{CO}_{2}$. This figure is then multiplied by the number of allowances $(20 \%$ in each allocation variant) which have to be purchased via auctioning [34].

\subsection{Allocation Variants}

The objective of the present paper is to compare various allocation possibilities and calculate the resulting monetary burden for the waste sector and its four industries. This is needed in order to assess the impact of future inclusion of the Austrian waste sector in the EU ETS. Three different allocation variants are covered (see Table 3).

Variant 1 assumes a climate protection contribution factor of 0 percent: The business-as-usual emissions value in 2020 need not to be reduced at all within the trading period 2013-2020. An auctioning share of $20 \%$, a reserve factor of $1 \%$, a reduction potential factor of 1 and a price per ton of $\mathrm{CO}_{2}$ emission of $€ 14.68$ is assumed. In order to make the calculation not too complex, a discount rate for future costs of 0 is assumed.

Variants 2 and 3 assume respective climate protection

Table 3. Distribution of emission allowances and financial burdens for all three allocation variants for the period $2013-2020$.

\begin{tabular}{|c|c|c|c|c|c|}
\hline $\begin{array}{l}\text { Allocation } \\
\text { Variants }\end{array}$ & $\begin{array}{l}\text { Total quantity of waste } \\
\text { sector's emission } \\
\text { allowances distributed }\end{array}$ & $\begin{array}{c}\text { Quantity of sector's emission } \\
\text { allowances allocated free of } \\
\text { charge/via auctioning }\end{array}$ & Waste sector's Industries & $\begin{array}{l}\text { Quantity of industry's } \\
\text { emission allowances }\end{array}$ & $\begin{array}{c}\text { Monetary burden } \\
\text { per industry }\end{array}$ \\
\hline \multirow{7}{*}{$\begin{array}{l}\text { Variant } 1 \\
\text { (Climate } \\
\text { protection } \\
\text { contribution } \\
0 \% \text { ) }\end{array}$} & \multirow{8}{*}{$\begin{array}{c}\text { Total allowances } \\
11,561,880\end{array}$} & \multirow{4}{*}{ Allocated for free $9,249,504$} & Landfills & $6,306,854$ & \\
\hline & & & Composting facilities & $1,028,966$ & \\
\hline & & & Incineration facilities & 76,032 & \\
\hline & & & Wastewater handling & $1,837,651$ & \\
\hline & & \multirow{8}{*}{ Allocated for free 8,787,029 } & Landfills & $1,576,714$ & $€ 23,150,231$ \\
\hline & & & Composting facilities & 257,242 & $€ 3,776,972$ \\
\hline & & & Incineration facilities & 19,008 & $€ 279,087$ \\
\hline \multirow{8}{*}{$\begin{array}{c}\text { Variant } 2 \\
\text { (Climate } \\
\text { protection } \\
\text { contribution } \\
5 \% \text { ) }\end{array}$} & & & Wastewater handling & 459,413 & $€ 6,745,367$ \\
\hline & \multirow{8}{*}{$\begin{array}{c}\text { Total allowances } \\
10,983,786\end{array}$} & & Landfills & $5,991,512$ & \\
\hline & & & Composting facilities & 977,518 & \\
\hline & & & Incineration facilities & 72,230 & \\
\hline & & & Wastewater handling & $1,745,769$ & \\
\hline & & \multirow{4}{*}{$\begin{array}{l}\text { Auctioning } 2,196,757 \\
\quad(€ 32,254,074)\end{array}$} & Landfills & $1,497,878$ & $€ 21,992,720$ \\
\hline & & & Composting facilities & 244,380 & $€ 3,588,123$ \\
\hline & & & Incineration facilities & 18,058 & $€ 265,132$ \\
\hline \multirow{9}{*}{$\begin{array}{c}\text { Variant } 3 \\
\text { (Climate } \\
\text { protection } \\
\text { contribution } \\
10 \% \text { ) }\end{array}$} & & & Wastewater handling & 436,442 & $€ 6,408,099$ \\
\hline & \multirow{8}{*}{$\begin{array}{c}\text { Total allowances } \\
10,405,692\end{array}$} & \multirow{4}{*}{$\begin{array}{l}\text { Allocated for free } \\
\qquad 8324554\end{array}$} & Landfills & $5,676,169$ & \\
\hline & & & Composting facilities & 926,070 & \\
\hline & & & Incineration facilities & 68,429 & \\
\hline & & & Wastewater handling & $1,653,886$ & \\
\hline & & & Landfills & $1,419,042$ & $€ 20,835,208$ \\
\hline & & Auctioning 2,081,138 & Composting facilities & 231,517 & $€ 3,399,274$ \\
\hline & & $(€ 30,556,491)$ & Incineration facilities & 17,107 & $€ 251,178$ \\
\hline & & & Wastewater handling & 413,472 & $€ 6,070,831$ \\
\hline
\end{tabular}

Source: Own composition. 
contribution factors of $5 \%$ and $10 \%$. Thus, the respective business-as-usual emissions value in 2020 needs to be reduced by between $5 \%$ and $10 \%$ within the trading period 2013-2020. All the other factors are held at the levels stated for the first variant.

The remaining data needed for modeling, such as the allocation base, the business-as-usual forecast, the emission projection and the growth factor, are calculated and presented in Tables 1 and 2.

\section{Results}

The model results for all three allocation variants calculated (i.e. depending on the level of climate protection contribution factor) are presented in Table 3 . The monetary value stated in brackets, directly below the amount of emission allowances to be obtained via auction, is based on the average price of $€ 14.68 / \mathrm{t} \mathrm{CO}_{2}$ [34] for the six month period from March to August 2011.

\section{Discussion and Conclusion}

The results show that the Austrian waste sector would receive between 11.5 million and 10.4 million emission allowances in total, depending on whether the climate protection contribution is $0 \%$ or $10 \%$. These amounts consist of 9.2 to 8.3 million allowances, allocated free of charge and 2.3 to 2.0 million allowances which would have to be auctioned. Under the assumption of constant prices, the additional purchase via auction would lead to a financial burden of between $€ 33.9$ million and $€ 30.5$ million.

Considering the relative proportions of emission allowances to business-as-usual emissions in the current energy and industrial sector in Austria in the first trading period (i.e. 1:1.41 and 1:1.15 respectively), it can be seen that the first two allocation variants have an similar proportion (1:1.41 and 1:1.49) [22,31]. Thus it would make sense to set the climate protection contribution between $0 \%$ and 5\% for the Austrian waste sector, assuming the distribution is to be in proportion to that of the energy and industrial sectors. At such climate protection contribution levels the Austrian waste sector would receive between 11.5 million and 10.9 million allowances, leading to additional costs of $€ 33.9$ million and $€ 32.2$ million, respectively, in the initial phase of the allocation process.

The present paper has attempted to provide some insights into the economic modeling of allocating emission allowances as well as into the interface between the European Union Emissions Trading Scheme and the Austrian waste sector.

Due to the fact that inclusion of the waste sectors in the EU ETS has not yet been finalized, for the purposes of the present calculation the underlying assumptions were deliberately kept simple. The present analysis serves merely to offer a tentative estimate regarding both quantities of expected emission allowance allocations and their respective financial burdens. Should inclusion of the Austrian waste sector in the EU ETS move closer to becoming a reality, several further points would then need careful consideration.

One such point is that the calculation of the monetary burden assumes an unchanging price for all additional emission allowances purchased. Clearly, this is not realistic since prices are likely to fluctuate over time. While the use of an average price for allowances goes some way towards compensating for this effect, predicting developments in the need for allowances still remains somewhat problematic. (see, e.g., [3,5,7,11,35])

The marginal abatement costs (MAC) for waste sector agents were not taken into account in the present analysis or to put it more exactly, it was assumed that they were higher than the price for emission allowances. Thus, in order to compare the MAC with the $\mathrm{CO}_{2}$ price a separate study would be necessary to determine the relative MAC for the single industries and to assess the various treatment techniques in the waste sector. However, ignoring the MACs in the analysis above meant that it was possible to calculate expected financial burden simply on the basis of the quantity of emission allowances allocated. (see, e.g., [7,11,36]

A further aspect which was not taken into consideration above is the potential need for further emission allowance purchases in excess of the mandatory 20\% auction share. However, it appears likely that under a more auction-based allocation scheme, deviations between additional emission allowance demand and overall allowance allocation will tend to decline $[6,13]$.

The question of how to deal with indirect emissions also requires careful consideration. In the present context, indirect emissions are those GHG emissions which are avoided as a result of recycling of waste material, energy recovery, and so on, and which are not accounted for in the waste sector. They lead to lower GHG emissions overall, mainly in sectors external to the waste sector. For example, an increase in the use of secondary raw material as a result of greater recycling would lead to lower GHG emissions in other sectors as they replace primary with secondary raw materials. [27] The main difficulty here, at least in terms of emission classification, lies in how the system boundaries and interfaces between the waste sector and other economic sectors are to be defined. While this question was largely ignored in the present paper, further attention should be drawn on that special area.

A last point worthy of note, relates to the fact that inclusion of the Austrian waste sector in the EU ETS might lead to an increase in revenues as well as in costs, at least 
for some players. If the waste sector causes fewer GHG emissions than expected, the internal demand for emission allowances may decrease, leading to the possibility of some agents gaining revenues by selling the superfluous emission allowances to other EU ETS sectors and/or players. Such a change in requirements would also affect the market price for emission allowances (see, e.g., $[6,7,35,37]$. How and to what extent this interdependency between internal emission reduction, supply and demand of emission allowances and their market price would affect the waste sector cannot be predicted and thus were not part of the present paper.

Clearly, considerable further research is needed in order to address all the points associated with inclusion of the Austrian waste sector in the EU ETS.

\section{Acknowledgements}

This study is part of a research project funded by Altstoff Recycling Austria AG and Saubermacher Dienstleistungs AG. The authors wish to thank them both for their constructive ideas and support, especially Christoph Scharff, Roland Pomberger, Dieter Schuch and Hannes KlampflPernold.

\section{REFERENCES}

[1] United Nations (UN), "Kyoto-Protocol to the United Nations Framework Convention on Climate Change,” 1998. http://unfccc.int/resource/docs/convkp/kpeng.pdf

[2] European Commission (EC), "Directive 2003/87/EC of 13 October 2003 of the European Parliament and of the Council Establishing a Scheme for Greenhouse Gas Emission Allowance Trading within the Community and Amending Council Directive 96/61/EC,” Brussels, 2003.

[3] D. Toke, “Trading Schemes, Risks and Costs: The Chase of the European Union Emissions Trading Scheme and the Renewables Obligation," Environment and Planning C: Government and Policy, Vol. 26, No. 5, 2008, pp. 938953. http://dx.doi.org/10.1068/c0728j

[4] F. Schuppert, "Climate Change Mitigation and Intergenerational Justice,” Environmental Politics, Vol. 20, No. 3, 2011, pp. 303-321.

http://dx.doi.org/10.1080/09644016.2011.573351

[5] S. Goers and B. Pflüglmayer, "Post-Kyoto Global Emissions Trading: Perspectives for Linking National Emissions Trading Schemes with the EU ETS in a Bottom-Up Approach,” Low Carbon Economy, Vol. 3, No. 3A, 2012, pp. 69-79. http://dx.doi.org/10.4236/lce.2012.323010

[6] M. Grubb and K. Neuhoff, "Allocation and Competitiveness in the EU Emissions Trading Scheme: Policy Overview," Climate Policy, Vol. 6, No. 1, 2006, pp. 7-30. http://dx.doi.org/10.1080/14693062.2006.9685586

[7] D. C. Matisoff, "Making Cap-and-Trade Work: Lessons from the European Union experience," Environment: Science and Policy for Sustainable Development, Vol. 52, No. 1, 2010, pp. 10-19.

\section{http://dx.doi.org/10.1080/00139150903479530}

[8] E. Gentil, T. H. Christensen and E. Aoustin, "Greenhouse Gas Accounting and Waste Management," Waste Management and Research, Vol. 27, No. 8, 2009, pp. 696706.

[9] European Commission (EC), "Directive 2008/101/EC of 19 November 2009 of the European Parliament and of the Council Amending Directive 2003/87/EC so as to Include Aviation Activities in the Scheme for Greenhouse Gas Emission Allowance Trading within the Community," Brussels, 2008.

[10] S. Perdan and A. Azapagic, "Carbon Trading: Current Schemes and Future Developments," Energy Policy, Vol. 39, No. 10, 2011, pp. 6040-6054. http://dx.doi.org/10.1016/j.enpol.2011.07.003

[11] A. Lepone, R. T. Rahman and J.-Y. Yang, “The Impact of European Union Emissions Trading Scheme (EU ETS) National Allocation Plans (NAP) on Carbon Markets," Low Carbon Economy, Vol. 2, No. 2, 2011, pp. 71-90. http://dx.doi.org/10.4236/lce.2011.22011

[12] European Commission (EC), "EU Action against Climate Change: The EU Emissions Trading Scheme,” Luxembourg, 2008.

[13] E. Benz, A. Löschel and B. Sturm, “Auctioning of $\mathrm{CO}_{2}$ Emission Allowances in Phase 3 of the EU Emissions Trading Scheme,” Climate Policy, Vol. 10, No. 6, 2010, pp. 705-718. http://dx.doi.org/10.3763/cpol.2009.0055

[14] European Commission (EC), "European Commission Website,” 2011. http://ec.europa.eu/clima/policies/ets

[15] PointCarbon, "Point Carbon's OTC Price Assessments," 2011. http://www.pointcarbon.com/

[16] B. Anderson and C. Di Maria, "Abatement and Allocation in the Pilot Phase of the EU ETS," Environmental and Resource Economics, Vol. 48, No. 1, 2011, pp. 83-103. http://dx.doi.org/10.1007/s10640-010-9399-9

[17] European Commission (EC), "Directive 2009/29/EC of 23 April 2009 the of the European Parliament and of the Council Amending Directive 2003/87/EC so as to Improve and Extend the Greenhouse Gas Emission Allowance Trading Scheme of the Community,” Brussels, 2009.

[18] M. Hiebel and H. Pflaum, "Recycling for Climate Protection- $\mathrm{CO}_{2}$-Emissions with the Utilisation of Secondary Raw Material in Comparison to the Use of Primary Raw Materials,” Müll und Abfall, Vol. 1, 2009, pp. 4-7.

[19] Intergovernmental Panel on Climate Change (IPCC), "Climate Change 2007: Synthesis Report. Contribution of Working Groups I, II and III to the Fourth Assessment Report of the Intergovernmental Panel on Climate Change,” Geneva, 2007.

[20] J. Bogner, R. Pipatti, S. Hashimoto, C. Diaz, K. Mareckova, L. Diaz, P. Kjeldsen, S. Monni, A. Faaij, Q. Gao, T. Zhang, M. Abdelrafie Ahmed, R. T. M. Sutamihardja and R. Gregory, "Mitigation of Global Greenhouse Gas Emissions from Waste: Conclusions and Strategies from the Intergovernmental Panel on Climate Change (IPCC) Fourth Assessment Report. Working Group III (Mitigation)," Waste Management and Research, Vol. 26, No. 1, 2008, pp. 11-32. 
[21] Environment Agency Austria (EAA), “Austria’s National Inventory Report: Submission under the United Nations Framework Convention on Climate Change and under the Kyoto Protocol,” REP-0308, Vienna, 2011.

[22] Environment Agency Austria (EAA), "GHG Projections and Assessment of Policies and Measures in Austria: Reporting Under Decision 280/2004/EC,” REP-0331, Vienna, 2011.

[23] European Parliament (EP), "Position of the European Parliament Adopted at First Reading on 17. December 2008 to Improve and Extend the Greenhouse Gas Emission Allowance Trading System by the Community," Consolidated Legislative Document, 2008.

[24] W. Winiwarter and K. Rypdal, “Assessing the Uncertainty Associated with National Greenhouse Gas Emission Inventories: A Case Study for Austria," Atmospheric Environment, Vol. 35, No. 32, 2001, pp. 5425-5440. http://dx.doi.org/10.1016/S1352-2310(01)00171-6

[25] Environment Agency Austria (EAA), “Austria’s National Inventory Report: Submission under the United Nations Framework Convention on Climate Change and under the Kyoto Protocol,” REP-0265, Vienna, 2010.

[26] S. Manfredi, D. Tonini, T. H. Christensen and H. Scharff, "Landfill of Waste Accounting of Greenhouse Gases and Global Warming Contributions," Waste Management and Research, Vol. 27, No. 8, 2009, pp. 825-836. http://dx.doi.org/10.1177/0734242X09348529

[27] C. Rootes, "Environmental Movements, Waste and Waste Infrastructure: An Introduction,” Environmental Politics, Vol. 18, No. 6, 2009, pp. 817-834. http://dx.doi.org/10.1080/09644010903345587

[28] M. Adam, H. Hentschke and S. Kopp-Assenmacher, "Handbuch des Emissionshandelsrechts" [Handbook of the Emissions Trading Law], Springer-Verlag, Berlin, 2006.

[29] D. Demailly and P. Quirion, " $\mathrm{CO}_{2}$ Abatement, Competitiveness and Leakage in the European Cement Industry under the EU ETS: Grandfathering versus Output-Based
Allocation,” Climate Policy, Vol. 6, No. 1, 2006, pp. 93113. http://dx.doi.org/10.1080/14693062.2006.9685590

[30] Federal Ministry for Agriculture, Forestry, Environment and Water Management, "National Allocation Plan for Austria Pursuant to Art.11 of the EZG,” Vienna, 2004.

[31] Federal Ministry for Agriculture, Forestry, Environment and Water Management, “Austria's National Allocation Plan Pursuant to Art.11 of the EZG for the Trading Period 2008-2012,” Vienna, 2007.

[32] Legal Information System of the Republic of Austria, Emissionszertifikategesetz (EZG), Bundesgesetzblatt für die Republik Österreich, 46. Bundesgesetz [Austria's Emissions Allowance Trading Act, BGBl. I Nr. 46/2004, 1-16] Vienna, 2004.

[33] Legal Information System of the Republic of Austria, Zuteilungsverordnung 2. Periode, Bundesgesetzblatt für die Republik Österreich, 279. Verordnung [Austria’s Ordinance on the Distribution of Emission Allowances for the Second Trading Period, BGBl. II Nr. 279/2007, 1-12] Vienna, 2007.

[34] European Energy Exchange (EEX), "EU Emission Allowances," 2011. www.eex.com

[35] W. Lise, J. Sijm and B. F. Hobbs, “The Impact of the EU ETS on Prices, Profits and Emissions in the Power Sector: Simulation Results with the COMPETES EU20 Model," Environmental and Resource Economics, Vol. 47, No. 1, 2010, pp. 23-44. http://dx.doi.org/10.1007/s10640-010-9362-9

[36] A. D. Ellerman and B. K. Buchner, "Over-Allocation or Abatement? A Preliminary Analysis of the EU ETS Based on the 2005-06 Emissions Data," Environmental and Resource Economics, Vol. 41, No. 2, 2008, pp. 267-287. http://dx.doi.org/10.1007/s10640-008-9191-2

[37] S. Monjon and P. Quirion, "A Border Adjustment for the EU ETS: Reconciling WTO Rules and Capacity to Tackle Carbon Leakage,” Climate Policy, Vol. 11, No. 5, 2011, pp. 1212-1225.

http://dx.doi.org/10.1080/14693062.2011.601907 